\title{
Molecular Diversity among Wild Edible Oyster Mushroom (Pleurotus spp.) from Western Ghat of Maharashtra
}

\author{
Phadke Monika Vilas", A. C. Jadhav, M. C. Dhavale, S. N. Hasabnis, \\ A. P. Gaikwad, P. R. Jadhav and Patil Savita Ajit \\ Agricultural Microbiology, Mahatma Phule Krishi Vidyapeeth, Rahuri, India \\ *Corresponding author
}

\section{Ke ywords \\ Mushroom, Molecular diversity, markers, Cluster, amplification}

Article Info

Accepted: 12 October 2020 Available Online: 10 November 2020

\section{A B S T R A C T}

Oyster mushroom is well known for its culinary properties and broad adaptability under varied agro-climatic conditions. Representatives of genus Pleurotus form a heterogeneous group of edible species of high commercial importance. However, there are many problems in taxonomy of Pleurotus spp. which are still unresolved. The concept of naming species on the basis of morphological characteristics has been dominant in the fungal taxonomy. However, morphological features of higher fungi are inconsistent as they are strongly influenced by cultivation substrate and environmental conditions. Consequently, different taxonomists have given different concepts and conclusions for the same taxon on the basis of morphological features. Molecular markers being enormous in number have a property of not being affected by the environment; make them a useful tool for understanding phylogenetic relationships as well as taxonomic identification. Mushroom is a macro fungus with a distinctive fruiting body which can be either epigeous or hypogenous and large enough to be seen with naked eye and to be picked by hand. The diverse climatic condition in India made this country a natural habitat for many mushrooms. The oyster mushroom (Pleurotus spp.) is highly suitable for commercial cultivation in subtropical regions of the world. They occur seasonally all over the world in various habitats such as humus rich soils, decaying plant litter and wood logs in forests as well as in meadows. The current study deals with "Molecular diversity among wild edible oyster mushroom (Pleurotus spp.) from western ghat of Maharashtra." It includes the collection of isolates from AICRP on mushroom, college of Agriculture Pune. The major part of the investigation was the molecular characterization. In molecular characterization, Inter Simple Sequence Repeat markers were used to determine the genetic diversity among Pleurotus isolates. Under ISSR analysis, out of 50 primers screened, UBC-807, UBC-808, UBC-809, UBC-817, UBC-825, UBC-827, UBC-830, UBC-835, UBC-841 showed polymorphism and were selected for amplification. Cluster analysis of scorable ISSR bands generated a dendrogram revealing high genetic diversity in Pleurotus isolates and categorized 11 isolates into two clusters using 62 per cent similarity as a cut-off point. The average PIC value for the nine ISSR markers was obtained as 0.92 . Results showed that primers namely UBC-809, UBC-817, UBC-825, UBC-827 and UBC-835 have above average PIC value and were to be more informative. 


\section{Introduction}

The word mushroom is derived from the Greek word for fungi and moulds. Mushrooms are non-timber forest products which are often found as saprophytes on soil, open fields, farm lands, woods and road sides. Around 1650, a melon grower near Paris discovered mushrooms growing on his melon field. Fungi were most likely cultivated for the first time around the year 600 in Asia. In Europe, the first cultivated fungi, the mushroom was introduced in the $17^{\text {th }}$ century. Mushrooms were introduced in the Netherlands for the first time at the beginning of the $19^{\text {th }}$ century. After 1900's, mushrooms were cultivated on a large-scale in the marl mines in Limburg.

Serious efforts on mushroom research and extension work in India were started in the early sixties through a scheme entitled "development of mushroom cultivation in Himachal Pradesh". In 1983, ICAR has established the National Centre for Mushroom Research and Training at Solan (Himachal Pradesh). Earlier it was thought that the hills were the most suitable place for mushroom cultivation. However, later it was realized that an indoor crop like mushroom could be equally cultivated other than hills.

Pleurotus species constitute one of the choicest edible mushrooms, commonly known as 'Oyster Mushroom' and in India recognized by the name 'Dhingri Mushroom'. It grows naturally in the temperate and tropical forests on dead and decaying wooden $\operatorname{logs}$ or sometimes on dying trunks of deciduous or coniferous woods. It may also grow on decaying organic matter. The fruiting bodies of the mushrooms are distinctly shell or spatula shaped with different shades of white, cream, grey, yellow, pink or light brown depending upon the species. Species of Pleurotus are widely known as efficient decomposers of a large range of agricultural wastes and produce edible basidiomycota of high organoleptic qualities. These properties favored significantly the spread of their commercial cultivation which recently accounted for about a quarter of the total world mushroom production (Chang and Miles, 1991).

Molecular markers being enormous in number have a property of not being affected by the environment; make them a useful tool for understanding phylogenetic relationships as well as taxonomic identification.

The ribosomal DNA contains one transcriptional unit with a cluster of genes coding for $18 \mathrm{~S}, 5.8 \mathrm{~S}$ and $28 \mathrm{~S}$ rRNA's and two internal transcribed spacers, which are useful in measuring a genealogical relationship because of the conserved sequences present in the rDNA region with greater interspecies differences. Hibbet (1992) reported that different regions of rDNA evolve at variable rates, making them useful for phylogenetic studies among closely or distantly related organisms. Molecular phylogenetic studies in mushrooms have been largely based on Restriction fragment length polymorphism (RFLP) and Random amplified polymorphic DNA (RAPD).

New additions to the Pleurotus family, are the newly identified Pleurotus opuntiae and $P$. cystidiosus. Different species of oyster mushrooms are still distinguished, based on the colour, texture and taste of fruiting bodies. Only few species are identified at genus and species level. There is almost need of advance technique used for species identification beyond morphological and physiological criteria, because these characteristics are highly influenced by environmental conditions. The expression of particular gene is a cumulative outcome of environment and genetic makeup of a species/strain (Kumar, 
1999; Astarini et al., 2004). Biochemical markers can be a source to reflect the genetic study because they are direct product of genes.

DNA finger printing is also one of the efficient tools of plant biotechnology used for the assessment of genetic diversity (Mehmood et al., 2008). For long, different DNA markers along with morphological traits have been used for the determination of species at molecular level (Sajida et al., 2009).

The genetic study of mushroom has been worked out using molecular markers especially polymerase chain reaction (PCR). The use of molecular tools is almost essential to ensure that the inoculum used is from the correct species. Molecular tools provide more accurate methods for identification, than the few characters afforded by the traditional morphological features. Molecular markers, PCR and non-PCR based, are the widely used techniques for mushroom identification and characterization. However, direct sequencing of PCR product of repetitive nuclear DNA of mushrooms is a powerful tool for identification and phylogenetic studies basidiomycota and/or in mycelial cultures / several species of the genus.

The genus Pleurotus is also one of the most diverse groups among cultivated fungi with many taxonomic problems. According to Zervakis and Balis (1996), the taxonomic disagreements in the genus Pleurotus have risen for the following reasons:

Initial misidentification, Absence of type specimens,

Instability of morphological characters due to environmental changes,

Limited reports on physiological characteristics,

Lack of mating compatibility studies.
Thus, to clarify the taxonomic status of species in the genus Pleurotus (earlier determined mainly by morphological features), many researchers started to classify these fungi also by genomic criteria. As all other cultivated fungi, the cultivated lines of Pleurotus sp. can undergo a drastic loss of diversity resulting from man's selection. This genetic erosion increases genetic vulnerability and it may lead to dramatic effects on the production yield during cultivation.

The development of tools aimed at the clearcut and safe identification, and assessment of genetic variability of the wild and cultivated strains is thus a fundamental goal of molecular genetics research.

The crucial challenge in developing new methods for tracking microorganisms and their identification is to acquire rapidly. Markers have a high level of discriminative power and inter-laboratory reproducibility for specific and sensitive detection of a target organism in complex environmental or commercial samples. Markers based on amplified fragment length polymorphisms (AFLP) have potential in this respect.

Considering these points, it has been thought to undertake a research work on study on diversity among Pleurotus spp. by using molecular techniques with following objectives that includes to study the variability of wild edible oyster mushroom (Pleurotus spp.) on different media. To study the physiological variability of wild edible oyster mushroom (Pleurotus spp.). To study the molecular diversity of wild edible oyster mushroom (Pleurotus spp.) by PCR based technique.

\section{Materials and Methods}

The present investigation "Molecular Diversity among wild Edible Oyster 
Mushroom (Pleurotus spp.) from western Ghat of Maharashtra" was conducted at All India Coordinated Research Project on Mushroom, College of Agriculture, Pune, Biotechnology Laboratory College of Agriculture, Pune and Department of Plant Pathology, College of Agriculture Pune. The details of the material used, methodology and statistical procedure followed during the course of investigation are described in this chapter.

The experimental material for the study consisted of 11 isolates of Oyster mushroom (Pleurotus spp.) received from All India Coordinated Research Project on Mushroom, College of Agriculture, Pune Maharashtra. The list of isolates is presented in Table No. 1.

\section{Pure isolates}

The present study was limited to only Pleurotus spp. The pure isolates were maintained on the slants of malt extract agar under aseptic condition which were collected in survey during monsoon of year 2017-18 from different forests of northern Maharashtra, including Sahyadri and Satpura valley regions.

\section{Culture media}

Potato Dextrose Agar (PDA) and Malt Extract Agar (MEA) media were used for sub culturing of different wild oyster isolates.

\section{Methodology of DNA Extraction}

For the growth of mycelium mat bit of fungus were inoculated in malt extract broth in 250 $\mathrm{ml}$ flask. Flasks were kept in BOD incubator at $280^{\circ} \mathrm{C}$. After 8 days of inoculation growth will observed sufficiently. In aseptic condition it was taken from flask approximately $100 \mathrm{mg}$ which is dried on blotting paper. For DNA Extraction mycelia isolates were raised in liquid broth medium (malt Extract: $20 \mathrm{gm}$, water 1 Litre) for 8-10 days at $28^{\circ} \mathrm{C}$. Total genomic DNA was extracted as described by Doyle and Doyle, 1987 with some modification.

$100 \mathrm{mg}$ mat of fungus were crushed in a mortar and pestle using liquid nitrogen LiquidN2).

While crushing, $1 \mathrm{ml}$ of CTAB extraction buffer along with small quantity of Polyvinyl pyrrolidone (PVP) were added to the crushed sample and mixed it properly and transferred it to a centrifuge tube.

Then tubes were incubated at $65{ }^{\circ} \mathrm{C}$ for 45 minutes in water bath with occasional mixing.

Chloroform: Isoamyl alcohol (24:1) was added in equal volume and mixed by gentle inversion for 5-6 times. (This step was repeated twice)

These tubes were centrifuged at $10000 \mathrm{rpm}$ for 10 minutes in a centrifuge machine.

The contents got separated into three distinct phases. The aqueous phase containing DNA was pipetted out and added equal volume of chilled iso- propanol, $100 \mu \mathrm{l} 3 \mathrm{M}$ sodium acetate to it and incubated at $-20{ }^{\circ} \mathrm{C}$ for overnight.

On the next day the solution was centrifuged at $10000 \mathrm{rpm}$ for 10 minutes.

Pellet was collected and washed with $100 \mu \mathrm{l}$ of $70 \%$ ethanol and centrifuged at 10000rpm for 10 minutes.

Pellet was air dried and dissolved in $50 \mu 1$ of $1 \mathrm{X}$ TEbuffer. This DNA was stored at $-20^{\circ} \mathrm{C}$ for further use. 


\section{DNA purification}

Purification of DNA samples was done to remove RNA, proteins and polysaccharides which were the major contaminants. RNA and proteins were removed with RNase A and Proteinase $\mathrm{K}$ treatment, respectively. $1 \mu \mathrm{l}$ of RNase $\mathrm{A}$ and Proteinase $\mathrm{K}$ was added to the DNA sample and incubated at $37^{\circ} \mathrm{C}$ for 20 min. after each addition. The PVP used during extraction helps to elimination polysaccharides.

\section{Agarose gel electrophoresis}

DNA in the sample was separated on 0.8 per cent agarose gel.

\section{Procedure}

i. The Agarose gel electrophoresis unit was cleaned properly before use.

ii. Agarose gel $(0.8 \%)$ was prepared by dissolving $0.2 \mathrm{~g}$ of agarose in $25 \mathrm{ml} 1 \mathrm{X}$ TAE buffer and heated in microwave oven.

iii. Ethidium bromide $(3 \mu \mathrm{l})$ was added to it after cooling down to 45 to $50^{\circ} \mathrm{C}$

iv. The gel was poured in casting tray in which comb was inserted previously and kept for $30 \mathrm{~min}$

v. After solidification of the gel, the comb was removed.

vi. $5 \mu l$ of DNA was mixed with $1 \mu l$ of $6 \mathrm{X}$ gel loading dye and loaded on the gel.

vii. The electrophoresis was carried out at 3-4 V/cm for 45 min. using 1X TAE buffer.

viii. The gel was then visualized under gel documentation unit to check the results.

\section{DNA quantification and quality analysis}

All the DNA samples were quantified spectrophotometrically. Before taking sample readings, the instrument was set to zero with autoclaved distilled water as blank. the dna samples were diluted to $3 \mathrm{ml}$ for measuring the absorbnce in spectrophotometer at wavelength of $260 \mathrm{~nm}$ and $280 \mathrm{~nm}$. the $\mathrm{OD}_{260} / \mathrm{OD}_{280}$ ratios were recorded to assess the purity of DNA. A ratio of 1.8 for $\mathrm{OD}_{260} / \mathrm{OD}_{280}$ indicates good quality of DNA. The amount of DNA is calculated by using formula,

DNA $(n g / \mu l)=A 260 \times 50 \times$ dilution factor

Inter Simple Sequence Repeats (ISSR) Assay

Diversity analysis among (Pleurotus spp) was carried out using Inter Simple Sequence Repeats (ISSR) markers. ISSR assay was performed to detect the polymorphism in amplification pattern in the region between two Simple Sequence Repeats (SSR). This was carried out by amplifying the DNA with using specific primers relating to the SSR regions flanking the ISSR.

The good quality genomic DNA isolated from samples of the selected genotypes was subjected to ISSR assay. Total of Nine ISSR primers with good resolving power were selected after an initial primer screening (Table 2).

\section{PCR reaction for ISSR analysis}

The PCR reaction was be set for $20 \mu \mathrm{l}$ reaction volume given in table 3. Master Mix was prepared for each primer with the above reagents and divide into different PCR tubes (each tube $20 \mu \mathrm{l}$ ). $1 \mu \mathrm{l}$ of different genomic DNA samples will be added to master mix that lead to final quantity of $20 \mu \mathrm{l}$. PCR tubes 
will place in thermal cycler for amplification of the genomic DNA.

\section{Resolutions of amplified product}

The amplified products were run on 2.0 per cent agarose gel using $1 \mathrm{X}$ TAE buffer and stained with ethidium bromide along with DNA ladder. The profile was visualized under UV transilluminator and documented using gel documentation system. The documented ISSR profiles were carefully examined for polymorphism. Number of bands produced by each primer were counted and tabulated.

\section{Data Scoring and analysis}

Amplification profiles of different sub isolates with different primers were compared with each other and bands of DNA fragments scored manually as (1) or (0) depending on the presence or absence of a particular band, respectively. The data was analyzed using 1) Numerical Taxonomy System of Multivariate Statistical Programme (NTSYS) S.P. Joshi et al., (2000); software package. The dendrogram was constructed using Unweighted Pair Group Method of Arithmetic Averages (UPGMA).

\section{Results and Discussion}

Molecular diversity studies among wild edible mushroom Pleurotus spp. was carried out by conducting experiments during the year 201819 in the Laboratory of Plant Pathology, AICRP on Mushroom and Laboratory of Agricultural Biotechnology at College of Agriculture, Pune. The experiments included collection of oyster mushroom isolates; study of variation effects due to different media, $\mathrm{pH}$ levels and temperature regimes on mycelial growth. The molecular characterization of eleven isolates of Pleurotus spp. has been accomplished. The results thus obtained are presented in different sections of this chapter and discussed with comparing earlier reported findings.

\section{Molecular diversity analysis among oyster mushroom (Pleurotus spp)}

The molecular characterization of eleven isolates of Pleurotus mushroom was carried out by using nine Inter Simple Sequence Repeat (ISSR) markers. ISSR markers have high specificity, reproducibility, polymorphism and co-dominant nature, hence, have been used in many species for genetic analysis.

\section{DNA isolation, quantification and qualitative analysis}

Plant genomic DNA extraction protocol given by Doyle and Doyle, 1987 was used for extraction of DNA from eleven isolates of Pleurotus mushroom, a eukaryote, with some modification in buffer composition and methodology. Instead of using full grown mushroom, the mycelial growth of mushroom on broth was used for extraction of DNA. This helped in easy lysis of cell using liquid nitrogen and reduced the contamination of exudes.

The concentration of PVP and EDTA in CTAB extraction buffer was increased to $2 \%$ and $40 \mathrm{mM}$ respectively. Increased PVP reduced the polyphenolic contamination. While higher concentration of EDTA protected the DNA from degradation. Addition of $\mathrm{NaCl}$ at concentration $1.5 \mathrm{M}$ along with $2 \%$ CTAB helped in removing polysaccharides. The DNA was precipitated using isopropanol and spooled out (fishing) in fresh tube containing $70 \%$ alcohol to isolate DNA from impurities. The DNA isolated using this modifications was pure (Table 2) and stable.

The good quality and intact DNA was observed on $0.8 \%$ agarose gel. The 
quantification of isolated DNA was done by measuring absorbance at 260nm wavelength and purity was checked by taking the ratio of absorbance (A260/A280) using spectrophotometer. Total nucleic acid yield of the mushroom ranged from $300 \mathrm{ng} / \mu \mathrm{l}$ to 540ng/ $\mu 1$.

The A260/A280 ratio obtained using modified CTAB method in the range of 1.8 to 2.0 indicated that isolated DNA is highly pure with insignificant/low levels of proteins and polysaccharide contamination. The concentration of DNA of all the isolates and their respective ratio of A260/A280 is given (Table 2). The DNA was diluted to $40 \mathrm{ng} / \mu \mathrm{l}$ for PCR analysis.

\section{PCR reaction for ISSR primer}

The PCR amplification was done by using ISSR primers. Total of 20 ISSR primers were tried for PCR reaction out of which nine were selected based on reproducibility and sharpness of bands obtained. Annealing temperature for each of the primer pair was optimized by using different temperatures in gradient PCR (Table 3).

Based on consistency of bands, the optimum concentration of PCR reaction mixture was set and used for nine ISSR primers for studying the variability in eleven isolates of mushroom (Table 3).

\section{Molecular analysis using ISSR marker}

A total eleven Pleurotus isolates were tested for their genetic variability by using nine ISSR primers. These primers viz. UBC-807, UBC-808, UBC-809, UBC-817, UBC-825, UBC-827, UBC-830, UBC-835 and UBC-841 produced easily scorable and consistent banding patterns. The amplified products ranged from $100 \mathrm{bp}$ to $3000 \mathrm{bp}$. The nine ISSR primers generated a total of 141 alleles among eleven Pleurotus isolates which varied from ten to twenty-two with an average of 15 alleles per primer pair.

Out of 141 alleles generated by the ISSR primers, 141 alleles were polymorphic and no monomorphic, thus generating $100 \%$ polymorphism (Fig. 4). The amplified products were ranged from $100 \mathrm{bp}$ to $3000 \mathrm{bp}$. Analysis of the genetic coefficient, derived from the scores of ISSR marker showed that all isolates were highly polymorphic from each other.

\section{Polymorphic information content}

The nine ISSR primers used in the study generated 141 allele at an average of 15 alleles per primer without any monomorphic allele. Out of 141 allele obtained, 46 allele were unique for some isolates. Highest 11 unique bands were obtained using primer UBC-825 followed by primers UBC-827 and UBC-835 which gave 9 unique bands. Based on the scored bands for each primer, the PIC values of ISSR markers obtained.

It ranged from 0.86 to 0.97 . The highest PIC value of 0.97 was obtained for the primer UBC-825 and lowest 0.86 value was obtained for the primer UBC-841.

The average PIC value for the nine ISSR markers was obtained as 0.92 . Results showed that primers namely UBC-809, UBC-817, UBC-825, UBC-827 and UBC-835 have above average PIC value and were to be more efficient.

The PIC parameter helps to compare the information content of polymorphic ISSR primer and to select the most informative ISSR primer for best selection among different isolates. Values suggested that the set of ISSR primers used were capable of distinguishing different Pleurotus isolates. 
Table.1 List of 11 isolates of oyster mushroom (Pleurotus spp.)

\begin{tabular}{|l|l|l|l|l|l|}
\hline Sr. No. & Isolates & DMR accession No. & Sr. No. & Isolates & DMR accession No. \\
\hline $\mathbf{1 .}$ & PN-17-16 & DMRO-1026 & 2. & PN-17-23 & DMRO-1027 \\
\hline $\mathbf{3 .}$ & PN-17-30 & DMRO-1029 & 4. & PN-17-31 & DMRO-1030 \\
\hline $\mathbf{5 .}$ & PN-17-36 & DMRO-1033 & 6. & PN-17-55 & DMRO-1037 \\
\hline $\mathbf{7 .}$ & PN-18-9 & DMRO-1113 & 8. & PN-18-10 & DMRO-1114 \\
\hline $\mathbf{9 .}$ & PN-18-15 & DMRO-1116 & 10. & PN-18-38 & DMRO-1119 \\
\hline $\mathbf{1 1}$ & PN-18-50 & DMRO-1123 & & & \\
\hline
\end{tabular}

Table.2 DNA quantity (ng) of eleven isolates of Pleurotus spp.

\begin{tabular}{|c|c|c|c|c|c|}
\hline Sr. No. & $\begin{array}{l}\text { Isolate } \\
\text { Name }\end{array}$ & $\mathrm{OD}_{260}$ & $\mathrm{OD}_{280}$ & $\begin{array}{c}\text { Ratio } \\
\text { A260/A280 }\end{array}$ & $\begin{array}{c}\text { Concentration } \\
(\mathrm{ng} / \mu \mathrm{l})\end{array}$ \\
\hline 1 & PN-17-16 & 0.016 & 0.008 & 2.0 & 480 \\
\hline 2 & PN-17-23 & 0.016 & 0.008 & 2.0 & 480 \\
\hline 3 & PN-17-30 & 0.01 & 0.005 & 2.0 & 300 \\
\hline 4 & PN-17-31 & 0.015 & 0.0078 & 1.9 & 450 \\
\hline 5 & PN-17-36 & 0.015 & 0.0078 & 1.9 & 450 \\
\hline 6 & PN-17-55 & 0.018 & 0.0094 & 1.9 & 540 \\
\hline 7 & PN-18-9 & 0.011 & 0.0057 & 1.9 & 330 \\
\hline 8 & PN-18-10 & 0.011 & 0.0057 & 1.9 & 330 \\
\hline 9 & PN-18-15 & 0.017 & 0.0089 & 1.9 & 510 \\
\hline 10 & PN-18-38 & 0.010 & 0.005 & 2.0 & 300 \\
\hline 11 & PN-18-50 & 0.017 & 0.0085 & 2.0 & 510 \\
\hline
\end{tabular}

Table.3 Annealing temperature optimized for different ISSR primers

\begin{tabular}{|l|c|c|}
\hline Sr.No & Name of the primer. & Annealing Temp $\left({ }^{\mathbf{0}} \mathbf{C}\right)$ \\
\hline $\mathbf{1 .}$ & ISSR 7 & $\mathbf{5 0}$ \\
\hline $\mathbf{2 .}$ & ISSR 8 & $\mathbf{5 2}$ \\
\hline $\mathbf{3 .}$ & ISSR 9 & $\mathbf{5 2}$ \\
\hline $\mathbf{4 .}$ & ISSR 17 & $\mathbf{5 0}$ \\
\hline $\mathbf{5 .}$ & ISSR 25 & $\mathbf{5 0}$ \\
\hline $\mathbf{6 .}$ & ISSR 27 & $\mathbf{5 2}$ \\
\hline $\mathbf{7 .}$ & ISSR 30 & $\mathbf{5 2}$ \\
\hline $\mathbf{8 .}$ & ISSR 35 & $\mathbf{5 2}$ \\
\hline $\mathbf{9 .}$ & ISSR 41 & $\mathbf{5 2}$ \\
\hline
\end{tabular}


Fig.1 Dendrogram of 11 isolates of Pleurotus spp generated by UPGMA (Unweighted Pair Group Method with Arithmatic Mean) analysis with nine ISSR primers

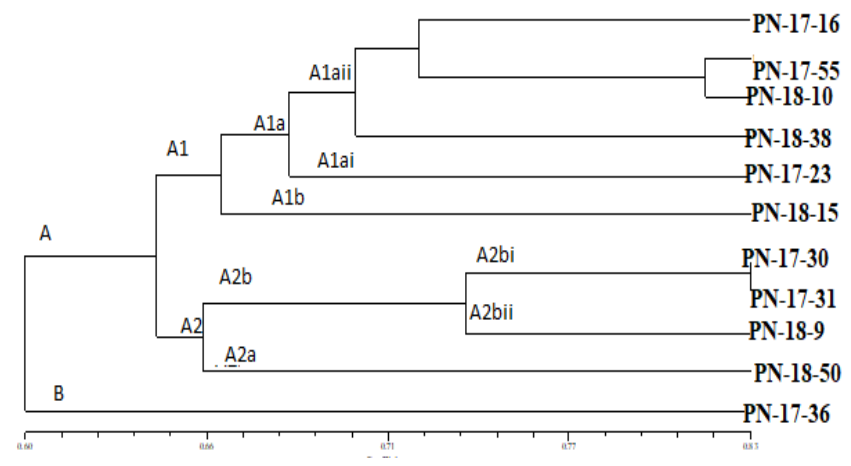

Fig.2 Dendrogram of 11 isolates of Pleurotus spp generated by Tocher method on the basis of three cultural characteristics

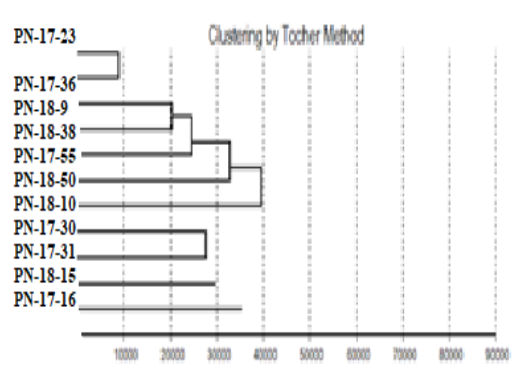

Fig.3

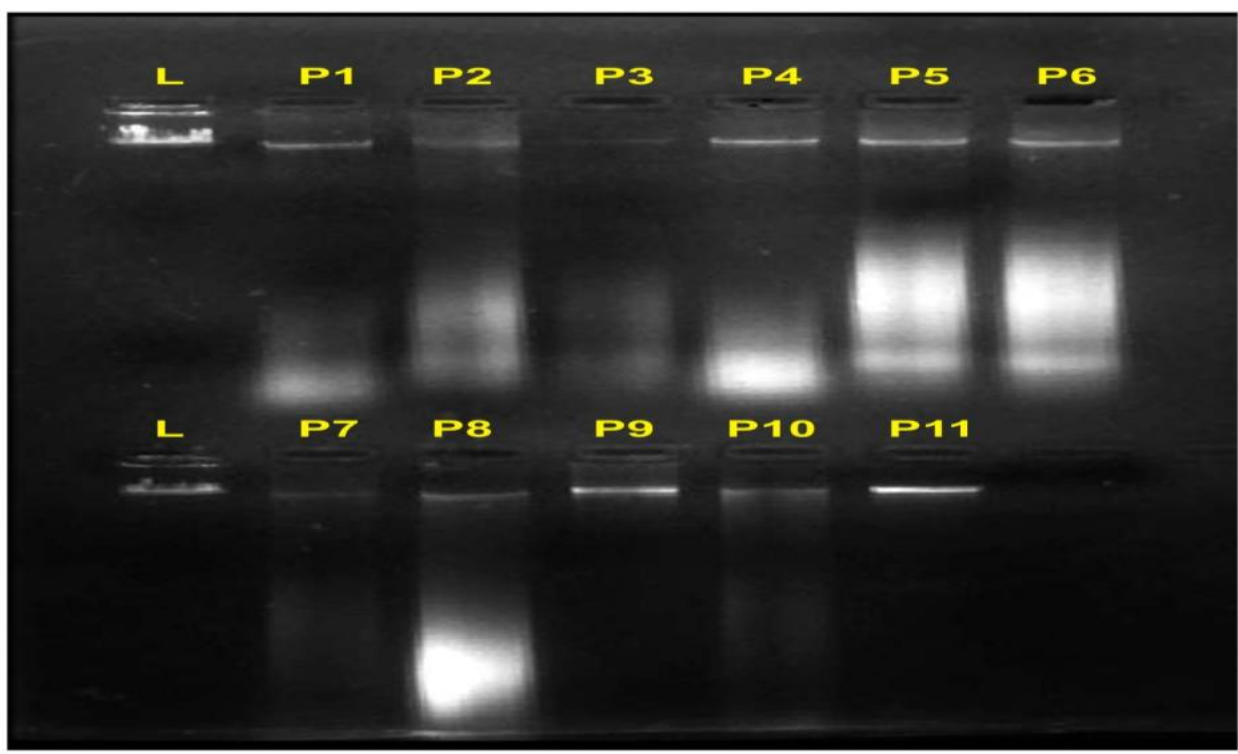

Plate11 = DNA isolated from eleven isolates of pleurous spp.

CL: $\lambda$ DNA (30 $\mathrm{mg}$, PI:PN-17-16, P2: PN-17-23, P3: PN-17-30, P4: PN-17-31, P5: PN-17-36, P6: PN-17-55, P7: PN-18-9,

P8: PN-18-10, PG: PN-18-15, P10: PN-18-38, P11: PN-18-50.) 
Fig.4
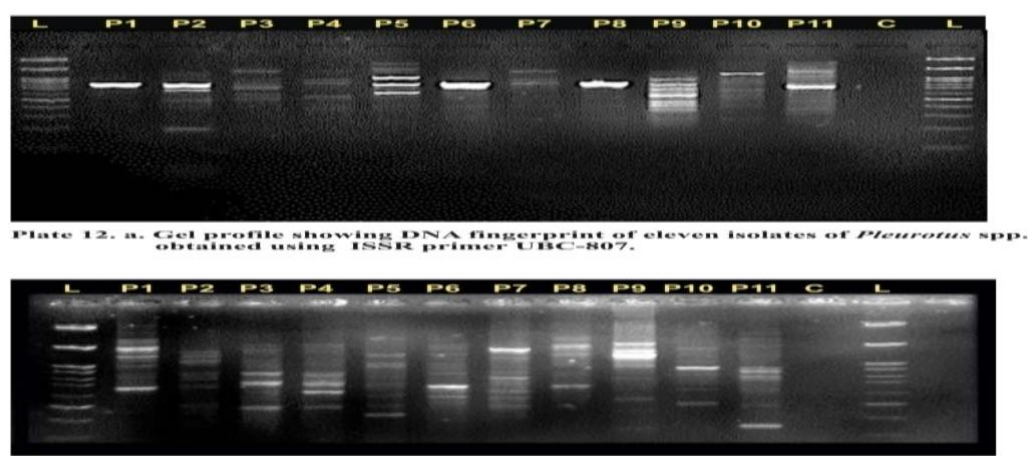

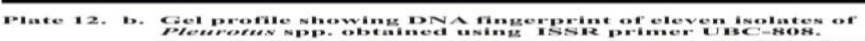
Whe

Fig.5

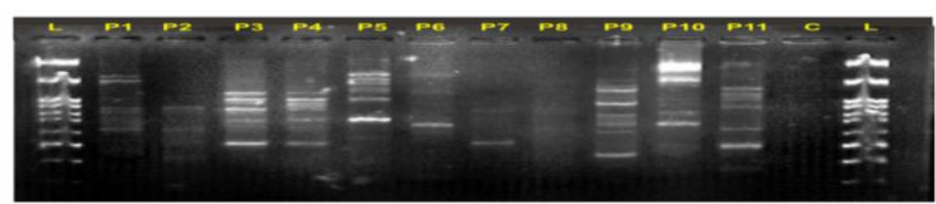

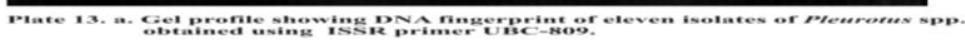

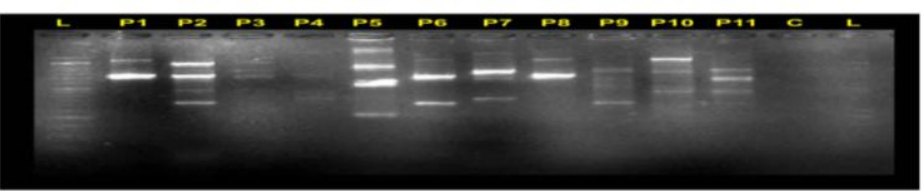

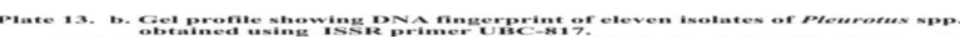

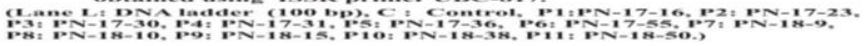

Fig.6

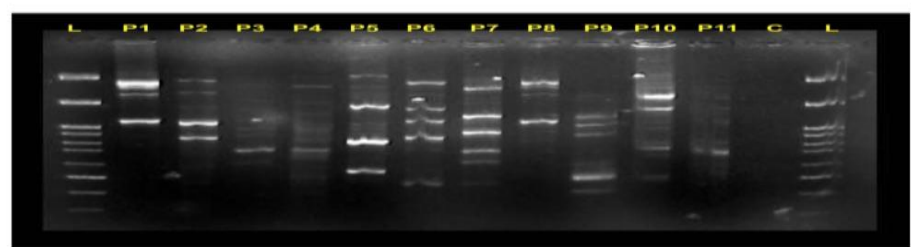

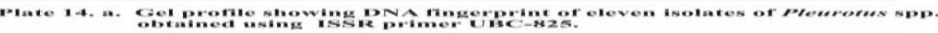

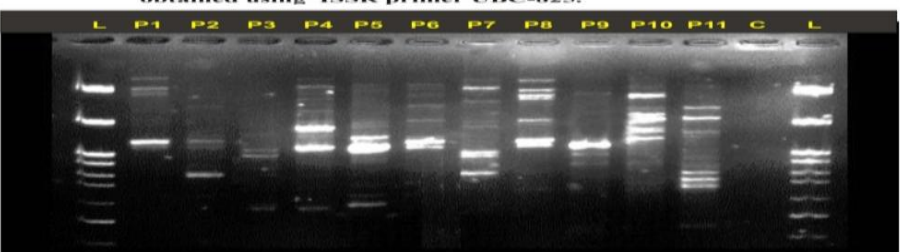

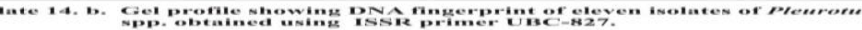
hand 
Fig.7

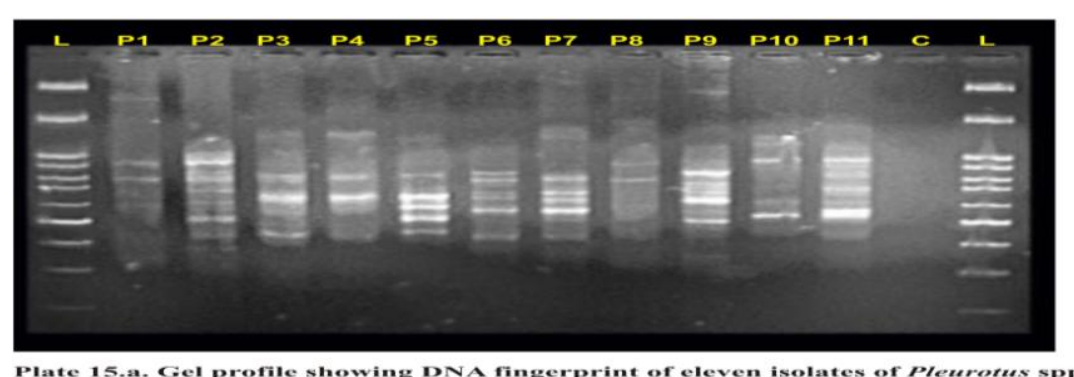

Plate 15.a. Gel profile showing DNA fingerprint of
obtained using ISST primer UBC-830.

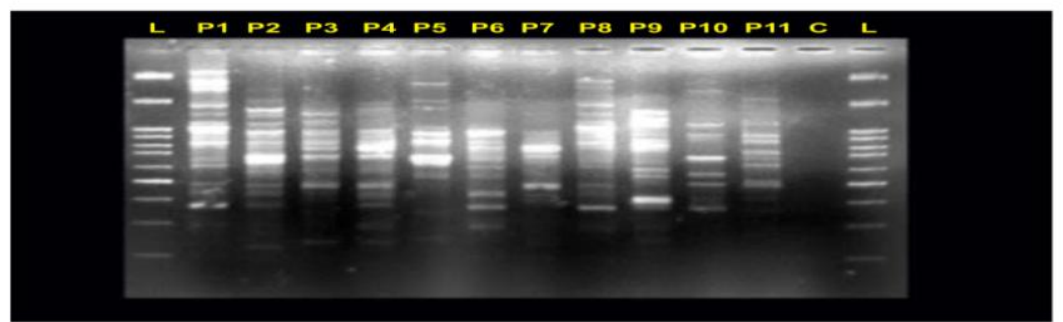

Plate 15. b. Gel profile showing DNA fingerprint of eleven isolates of pleurorus spp. Gane L: DNA ladder (100 bP), C C Control, P1:PN-17-16, P2: PN-17-23, P3: PN-17-30, P4: PN-17-31, P5: PN-17-36, P6: PN-17-55, 11 : PN-18-50.)

Fig.8

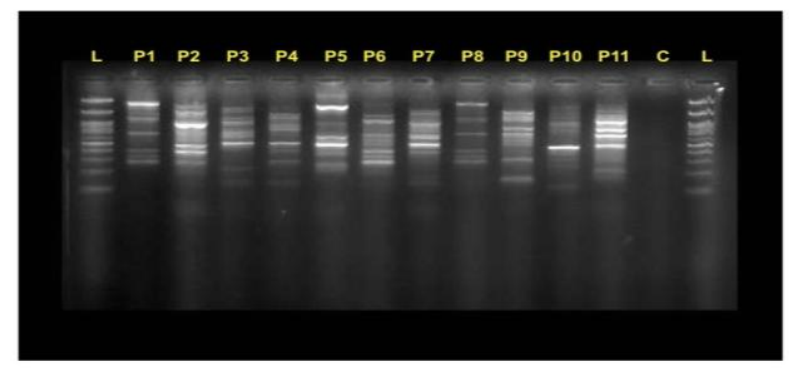

Plate 16. Gel profile showing DNA fingerprint of eleven isolates of Pleurotus spp. obtained using ISSR primer UBC-841.

(Lane L: DNA ladder (100 bp), C : Control, P1:PN-17-16, P2: PN-17-23, 76, PN-17-31, P5: PN-17-36, P6: PN-17-55, P7: PN-18-9. P8: PN-18-10, P9: PN-18-15, P10: PN-18-38, P11: PN-18-50.)

\section{Analysis of dendrogram}

Cluster analysis, using Unweighted PairGroup Method with Arithmetic Mean (UPGMA), gave a clear dendrogram for all the eleven Pleurotus isolates. The eleven isolates in the study showed $62 \%$ similarity and could be grouped in two broad groups based on Jaccard's coefficient generated on phylogenetic analysis using software NTSYS 2.0 (Fig. 1,2). The two broad groups were named 'A' and 'B' for convenience of explanation. Group A consisted of ten isolates (PN-17-16, PN-17-55, PN-18-10, PN-18-38, PN-17-23, PN-18-15, PN-17-30, PN-17-31, PN-18-9, PN-18-50) while group B had only 
one Pleurotus isolates PN-17-36. However, the isolate PN-17-36 did not show any peculiar distinctness in the cultural variation study. Culturally it may vary from rest 10 isolates but it needs to be further evaluated.

Cluster A was further separated in two sub clusters named A1 and A2 with 66\% similarity. Group A1 consisted of sub cluster $\mathrm{A} 1 \mathrm{a}$ and A1b. A1b cluster consisted of PN18-15. A1a further got divided into A1ai (PN17-23) and A1aii (consists of PN-17-16, PN17-55, PN-18-10, PN-18-38). A1aii was seen to be further divisible in small groups in which PN-17-55 and PN-18-10 were found to be closely placed with similarity of $81 \%$ growth rate. Group A2 got branched in two sub-groups A2a and A2b. Sub-group A2b further got divided into A2bi (PN-17-30, PN17-31 which were at $82 \%$ similarity.) and A2bii (PN-18-9). A2a divided into PN-18-50 (Fig. 2).

\section{Comparison between dendrogram of cultural and molecular characters}

The isolates $\mathrm{PN}-17-30$ and $\mathrm{PN}-17-31$ are closely related both by molecular and cultural characterization. The isolates PN-17-55 and PN-18-10 are closely related in the molecular characters while they are distinct from each other in cultural characters (Fig.3,4,5,6).

The isolates $\mathrm{PN}-17-23$ and $\mathrm{PN}-17-36$ are culturely closer whereas, at molecular level they are distant. The isolates PN-18-9 and PN-18-38 are culturally much similar whereas, are widely distant from each other at molecular level. In both cases molecular as well as cultural PN-17-16 and PN-18-15 are distant from each other (Fig.7,8).

In conclusion the mushrooms are macro fungi. Macrofungi are those fungi that form large fructifications visible without the help of a microscope and have easily observable spore-bearing structures. Mushroom is a food of high quality flavour and nutritional value and has high content of protein, low content of fat, vitamins, minerals and high content of fibers. Oyster mushroom (Pleurotus spp.) is popularly known as 'dhingri' in India and grows naturally in the temperate and tropical forests on dead and decaying wooden logs or sometimes on dying trunks of deciduous or coniferous woods. It may also grow on decaying organic matter. The fruiting bodies of this mushrooms are distinctly shell or spatula shaped with different shades of white, cream, grey, yellow, pink or light brown depending upon the species.

Investigation on "Molecular characterization of oyster mushroom (Pleurotus spp.) from western Ghat of Maharashtra" is carried out. The study included collection of isolates from AICRP on Mushroom, College of Agriculture Pune.

In molecular characterization, Inter Simple Sequence Repeat markers were used to determine the genetic diversity among Pleurotus isolates. Under ISSR analysis, out of 50 primers screened, UBC-807, UBC-808, UBC-809, UBC-817, UBC-825, UBC-827, UBC-830, UBC-835, UBC-841 showed polymorphism and were selected for amplification. Cluster analysis of scorable ISSR bands generated a dendrogram revealing high genetic diversity in Pleurotus isolates and categorized 11 isolates into two clusters using 62 per cent similarity as a cut-off point. Cluster analysis of scorable bands generated a dendrogram revealing high genetic diversity in Pleurotus isolates. The nine ISSR primers used in the study generated 141 alleles at an average of 15 alleles per primer without any monomorphic allele. Out of 141 alleles obtained, 46 alleles were unique for some isolates. Highest 11 unique bands were obtained using primer UBC-825 followed by primers UBC-827 and UBC-835 which gave 
9 unique bands. Based on the scored bands for each primer, the PIC values of ISSR markers obtained. It ranged from 0.86 to 0.97 . The highest PIC value of 0.97 was obtained for the primer UBC-825 and lowest 0.86 value was obtained for the primer UBC-841. The average PIC value for the nine ISSR markers was obtained as 0.92 . Results showed that primers namely UBC-809, UBC-817, UBC825, UBC-827 and UBC-835 have above average PIC value and were to be more informative.

\section{References}

Ahmad, I. Fuad, I. and Khan, Z. K. (2015). Mycelial growth of pink oyster (Pleurotus djamor) mushroom in different culture media \& environmental factors. AGR FOOD SCI., 2: 6-11.

Bresinsky, A., Hilber, O. and Molitoris, H. P. 1976. The genus Pleurotus as an aid for understanding the concept of species in Basidiomycetes. In : The species concept in Hymenomycetes. (ed. Clemenson H) Cramer, Vadiz, pp. 229-258.

Bao, D., Ishihara, H., Mori, N. and Kitamoto, Y. 2004. Phylogenetic analysis of oyster mushrooms (Pleurotus spp.) based on restriction fragment length polymorphisms of the 5' portion of 26S rDNA. "J. Wood Sci" 50: 169176.

Chang, S.T. and Buswell, J. A. (1996). Mushroom nutraceutically. World J. Microbiol. Biotechnol. 12: 473-476.

Chang,S. T. and Miles, P. G. (1991). Recent trends in wood production of edible mushrooms. The Mushroom J., 503: 15-18.

Chang, S. T.and Miles, P. G. (1992). Mushroom biology - a new discipline. The Mycologist, 6: 64- 65.

Khush, R.S., Becke, E. and Wach, W. 1992.
DNA amplification polymorphisms of the cultivated mushroom Agaricus bisporus. Appl. Environ. Microbiol. 58(9): 2971-2977

Kushwaha, K. P.S.; Singh, P. K.; Mishra, K. K. and Bhardwaj, S. B. (2011). Cultural and morphological studies of Hypsizygus ulmarius, blue oyster mushroom. Pantnagar J. Res, 9: 202205.

Lee, H.K., Shin, C.S., Min, K.B., Choi, K.S., Kim, B.G., Yoo, Y.B. and Min, K.H. 2000. Molecular systematics of the genus Pleurotus using sequence specific oligonucleotide probes. Science and Cultivation of Edible fungi. Proceedings of the 15 th International Congress on the Science and Cultivation of edible Fungi, Maastrict, Netherlands, 15-19. May. 207-213.

Lewinsohn, D., Nevo, E., Wasser, S.P., Hadar, Y. and Beharav, A. 2001. Genetic diversity in populations of the Pleurotus eryngii complex in Israel. Mycological Research 105 (8): 941951.

Liu, G., Liu, Z., Lia, J., Liu, L, Tai, L, Li, X., Zhu, H. and Zhu, L. 1995 Studies on fusants derived from intergeneric protoplast fusion of Pleurotus sapidus and Lentinus edodes by RAPD analysis.

Mohd, Z. (2012). Studies on morphological variability of oyster mushroom. SVPUA\&T, Meerut, Pp. 40-68.

Nayak, B. K. Bathmarajan, V. and Nanda, A. (2015). Effect of substrate and environmental parameters on the production of oyster mushroom in Pondicherry. Der Pharmacia Lettre, 7: 74-79.

Ragupathi, V., Kumerasan, S., Selvaraju, S. and Karthikeyan, S. (2016). Optimizing the growth conditions and adopting new methods growing oyster 
and milky mushrooms in same conditions. "Int. J. Herb Med", 4: 14.

Ram, R.C. and Pant, D.C. (2001). Effect of temperature and $\mathrm{pH}$ on mycelial growth of Pleurotus species. Indian J. Pl. Path., 19: 58-60.

Rout, M.K., Mohapatra, K.B.,Mohanty, P. and Chandan, S. S. (2015). Studies on effect of incubation temperature and light intensity on mycelial growth of oyster species. J. crop weed, 11: 4446.

Sardar, H., Muhammad, A. A., Chaudhary, M. A. and Rashid, A. (2015). Effects of different culture media, temperature and $\mathrm{pH}$ levels on the growth of wild and exotic Pleurotus species. Pakistan J. Phytopathology, 27: 139-145.

Singh, S.K., Rana, M.K. and Verma, R.N. 2000. Amplified DNA polymorphisms of cultivated mushrooms. Mushroom Res.9(1): 1925.

Turkovic (2015). Mycelial growth rate and yield of oyster mushroom - Pleurotus ostreatus fruitful part (Jacquin: Fr.) Kumm at different temperatures. Bulletin of the Chemists and Technologist of Bosnia and Herzegovina, 44: 53-58.

Uddin, M. J., Nasiruddin, K. M., Haque, M.
E., Biswas, A. K. and Islam, M. S. (2012). Influence of different media variety and growth regulator on mycelial colony proliferation of mushroom. J. Environ. Sci. Nat. Resour. 5: 223-227.

Urbanelli, S., Rosa, V.D., Punelli, F., Porretta, D., Reverberi, M., Fabbri, A.A. and Fanelli, C. 2007. DNA fingerprinting ( AFLP and RFLP ) for genotypic identification in species of the Pleurotus eryngii complex. APPL.GENET MOL BIOTECHNOL 74 : 592-600.

Virk, J. S. and Kapoor, S. (2016). Studies on nutritional requirements of different strains of king oyster mushroom (Pleurotus eryngii). Agric. Res. J., 53: 53- 56.

Yadav, M. K. and Chandra, R. (2014). Evaluation of culture media, $\mathrm{pH}$ and temperature for mycelial growth of different strains of Pleurotus sp. Agriculture Science Digest, 34: 299 302

Zervakis, G. I., Monslavo, J. M. and Vilgalys, R. 2004. Molecular phylogeny, biogeography and speciation speciation of the mushroom species Pleurotus cystidiosus and allied taxa. Microbiology 150: 715-726.

\section{How to cite this article:}

Phadke Monika Vilas, A. C. Jadhav, M. C. Dhavale, S. N. Hasabnis, A. P. Gaikwad, P. R. Jadhav and Patil Savita Ajit. 2020. Molecular Diversity among Wild Edible Oyster Mushroom (Pleurotus spp.) from Western Ghat of Maharashtra. Int.J.Curr.Microbiol.App.Sci. 9(11): 1394-1407. doi: https://doi.org/10.20546/ijcmas.2020.911.164 